\title{
AN ACCOMMODATIVE BALANCE TEST
}

BY

\author{
ERNEST E. MADDOX \\ BOURNEMOUTH
}

I AM indebted to Mr. Clifford Browne's ingenious and attractive Duochrome Test for the estimation of refraction in distant vision for suggesting in principle the following counterpart for near vision, which, however, is not a "punctum proximum" test, or even a refraction test. It consists of two tiny rectangles of paper, red and green respectively, one close above the other, with a little black lettering on each, and mounted either on the midclle of a black disc in an ordinary trial-lens ring, or on any punctum

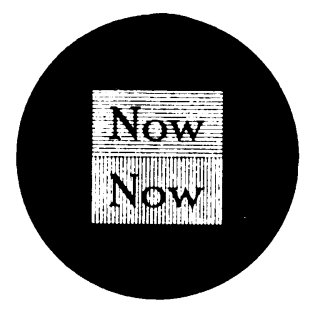

proximum measure. I have to thank Messrs. Theodore Hamblin, Ltd. for supplying me with appropriate paper and mounts for the experiment. The little appliance, as figured, is obtainable from them.

There are two ways of using the test. The first consists in making it gradually recede until the letterings on the two papers appear equally vivid. This will generally be found to take place considerably further away than the punctum proximum. The second and more useful method is to hold the little device at the patient's reading or working distance, while plus spheres are mounted up on the top of his static refraction until the letterings agree.

Let us ask now what is the significance of this test. It is, I believe, the converse of the rod and wing tests, which measure the balance of convergence in the presence of a fixed accommodation, since it measures the accommodative balance in the presence of a known convergence. In each case the mental knowledge of the distance of the object plays a part also.

The first mode of applying the test, by which the disc is caused to recede until the letterings tally, tells us the distance of what for want of a better word I will temporarily call synphoria, a 
condition in which the accommodative far point tends, at ease, to coincide with the point of intersection of the visual lines. The second (stationary) mode of applying the test tells us the accommodative phoria at the reading or working distance, a piece of information which ought to help us in the correction of presbyopia as soon as a sufficient number of experiments have been made.

It would be premature to make rules, at this stage, save only that when, at reading distance, the lettering on the red shows best, the presbyopic correction is too high. Thus, the red should be taken as a danger signal, while by how much the green should be allowed to predominate is a matter for investigation. The red indicates that the eye tends to be relatively myopic, and the green relatively hypermetropic, for the point of convergence.

The question: "Wherein exactly lies the difference between this new little test and the 'punctum proximum' test?" may be answered thus: The one is effortless, while the other demands the maximum of accommodative effort. On looking at the coloured papers the mind has no preference for one above the other, and accommodation simply "stands at ease" where it will. For the punctum proximum, on the contrary, the desire to see clearly under increasing difficulties is the provocation, and, as Duane says : "it is particularly important that the patient . . . . should accommodate with all his might." To put it shortly, one test measures the balance of accommodation, and the other its amplitude.

An interesting corollary of this little study is the sidelight it throws on the Clifford Browne distance test, showing that in theory it is not a pure refraction test, as has hitherto been supposed, however well it may work as such in practice. It is an "accommodative balance" test, and the symphoric point may or may not coincide with the punctum remotum, just as in the near test it never coincides with the punctum proximum. Happily, in far vision the coincidence is generally near enough for all practical purposes, and I use it, in the modified form of the Hamblin 2-colour distance test types, with much satisfaction. It is quite possible, however, that we mav come across cases of incoincidence in which the 2-colour test result differs a little from Snellen's types. 